\title{
Performance Evaluation of Small Wind Turbine Diffusers with Different Diameters
}

\author{
Sandip A. Kale, Rushikesh V. Godse, Haribhau G. Phakatkar
}

\begin{abstract}
Use of diffusers for increasing wind velocity is not a new concept. It is proven system through computational and experimental analysis carried out few researchers. Still, it is not well accepted technology and very few researchers are engaged in this research. Between computational and experimental analysis, researchers always prefer the computational flow analysis for evaluation of wind flow. The effect of diffuser diameter is an important aspect and this research paper is formulated on the same basis. In this research work straight conical converging -diverging vertical flanged diffusers are analyzed to study the performance. Ten different diffusers from $0.6 \mathrm{~m}$ to $6.0 \mathrm{~m}$ diameter are considered with the incremental step of $0.6 \mathrm{~m}$. For all diffusers same geometry is used and simulated at the wind velocity $6.5 \mathrm{~m} / \mathrm{s}$. All dimensions of these diffuser models are considered with the same proportional by taking the rotor diameter as a reference. The velocity counters are studied and plotted. The velocity values measured in throat plane are plotted for all diffusers. Also, the multiple increase in velocity, power and coefficient of performance is plotted and discussed.
\end{abstract}

Index Terms: CFD, diffuser augmented wind turbine, wind turbine.

\section{INTRODUCTION}

Wind turbine power output is mainly depending on the rotor diameter and wind velocity. Power produced by a wind turbine is proportional to the square of rotor diameter and cube of wind velocity. Hence, to obtain, the more power from wind turbine one need to increase either the rotor diameter or wind velocity [1]. Large wind turbine manufacturers are always interested in increasing the rotor diameter to get more power output and achieved satisfactory performance also. These wind turbines are installed and operating in the windy regions after micro-sitting and site selection. The wind speed available at these sites is capable of producing expected electricity satisfactorily and economically. Small wind turbines are situated in the sites where, wind speed is less than that of the large wind turbines. As the power produced is proportional to the cube of wind velocity, low wind velocity significantly reduces the power output of small wind turbines. The output of the small wind turbine can be effectively increased by increasing the wind velocity.

Revised Manuscript Received on April 12, 2019.

Sandip A. Kale, Mechanical Engineering Department, Trinity College of Engineering and Research, Savitribai Phule Pune University, Pune, India.

Haribhau G. Phakatkar, Mechanical Engineering Department, Trinity College of Engineering and Research, Savitribai Phule Pune University, Pune, India.

Rushikesh V. Godse, Mechanical Engineering Department, Trinity College of Engineering and Research, Savitribai Phule Pune University, Pune, India.
Covering the small wind turbines with diffusers is an efficient and economical method to increase the power output [2] [3]. Using diffusers for acceleration of wind speed to increase the power output is an old concept [4] [5]. Though this concept found very useful, the Diffuser Augmented Wind Turbines (DAWT) are still to be accepted by people because of some issues arise with the addition of the diffuser to the bare wind turbine [6] [7]. DAWT are more bulky, heavy and costlier than the bare wind turbine and also come across yawing performance. Because of advances in material sciences the intensities of these issues can be lowered considerably [8]. Researchers are always trying to reduce overall length and diameter of the diffuser without compromising the diffuser performance. Many researchers have carried out Computational Fluid Dynamics (CFD) analysis of diffusers of different geometries [9] [10].

This research work presents the wind flow study of straight conical convergent-divergent diffuser with vertical flange without rotor for diffusers with similar geometries but of different diameters.

\section{METHODOLOGY}

Table 1 shows the dimensions proportional of various geometrical parameters used for all diffuser diameters. Ten different rotor diameters are evaluated through the Computational Fluid Dynamic (CFD) analysis in this research paper. For all diffusers, input velocity is taken as 6.5 $\mathrm{m} / \mathrm{s}$. The minimum rotor diameter is considered for this study is $0.6 \mathrm{~m}$ and maximum diameter as $6 \mathrm{~m}$. The rotor diameters increase in the step of $0.6 \mathrm{~m}$. The ten diffusers are denoted as Diff $_{\mathrm{D}}$, where subscript $\mathrm{D}$ indicates diameter of diffuser in meters. For example Diff ${ }_{0.6}$ indicates diffuser model for $0.6 \mathrm{~m}$ rotor diameter.

Table I: Details of fixed dimensional parameters

\begin{tabular}{|l|l|l|}
\hline Wind turbine rotor diameter $(\mathrm{D})$ & $=$ & $\mathrm{D}$ \\
\hline Diffuser diameter at Inlet $\left(\mathrm{D}_{1}\right)$ & $=$ & $1.05 \mathrm{D}$ \\
\hline Diffuser diameter at Throat $\left(\mathrm{D}_{2}\right)$ & $=$ & $1.03 \mathrm{D}$ \\
\hline Diffuser diameter at Exit $\left(\mathrm{D}_{3}\right)$ & $=$ & $1.21 \mathrm{D}$ \\
\hline Flange Height $(\mathrm{H})$ & $=$ & $0.08 \mathrm{D}$ \\
\hline Diffuser Flange diameter $\left(\mathrm{D}_{4}=\mathrm{D}_{3}+2 \mathrm{H}\right)$ & $=$ & $1.37 \mathrm{D}$ \\
\hline Entry to Throat Length $\left(\mathrm{L}_{1}\right)$ & $=$ & $0.07 \mathrm{D}$ \\
\hline Throat to Exit Length $\left(\mathrm{L}_{2}\right)$ & $=$ & $0.25 \mathrm{D}$ \\
\hline Total Length of Diffuser $(\mathrm{L})$ & $=$ & $0.32 \mathrm{D}$ \\
\hline Rotor tip to throat Gap $(\mathrm{G})$ & $=$ & $0.015 \mathrm{D}$ \\
\hline
\end{tabular}
\[ \]
$\begin{aligned} & \text { Published By: } \\
& \text { Blue Eyes Intelligence Engineering } \\
& \text { \& Sciences Publication }\end{aligned}$




\section{COMPUTATIONAL FLOW ANALYSIS}

Fig. 1 (a) to Fig. 1 (j) shows the velocity counters for all ten diffusers for the inlet velocity $6.5 \mathrm{~m} / \mathrm{s}$.

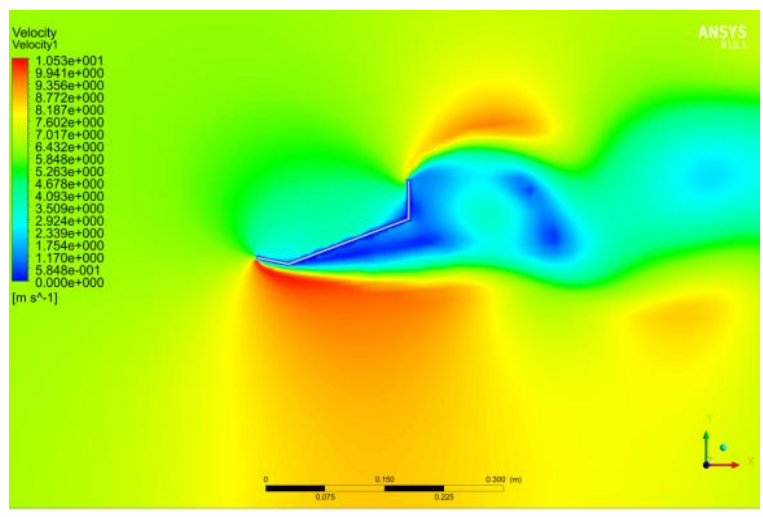

a. Velocity Counters for $\operatorname{Diff}_{0.6}$

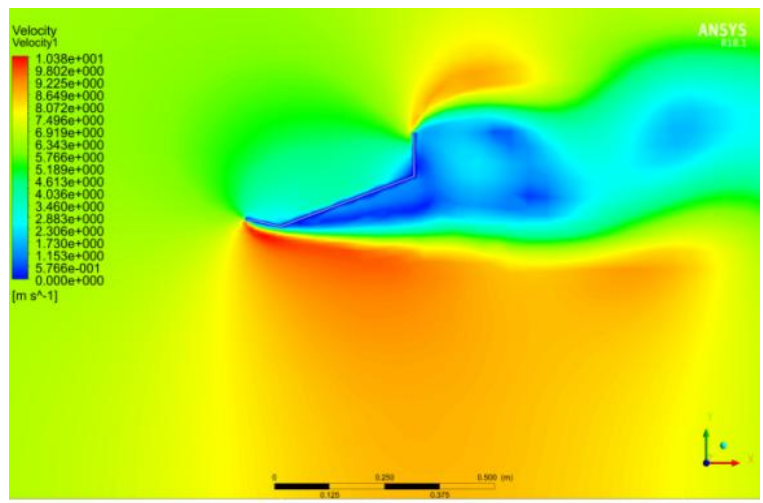

b. Velocity Counters for $\operatorname{Diff}_{1.2}$

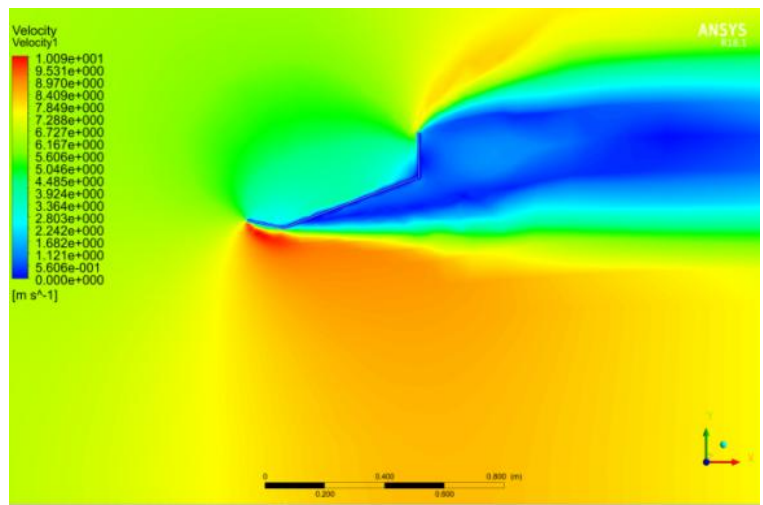

c. Velocity Counters for Diff 1.8

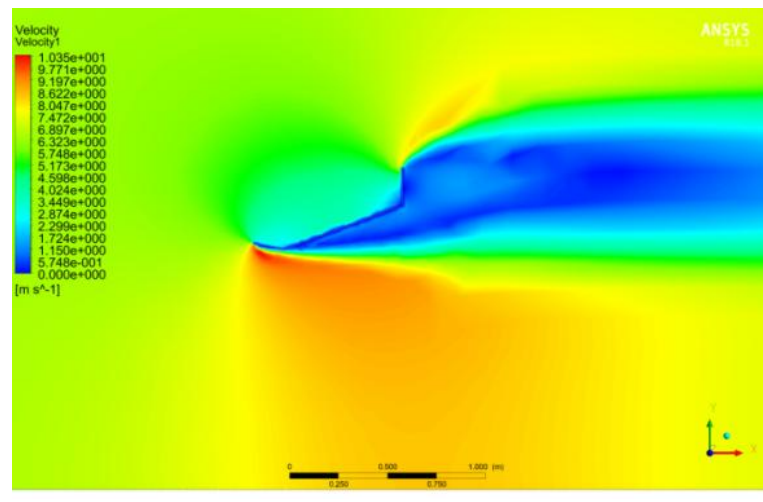

d. Velocity Counters for $\operatorname{Diff}_{2.4}$

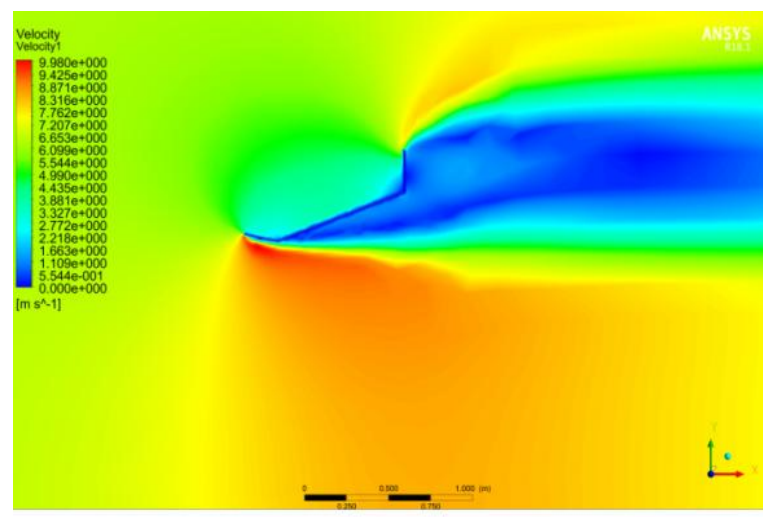

e. Velocity Counters for Diff $_{3.0}$

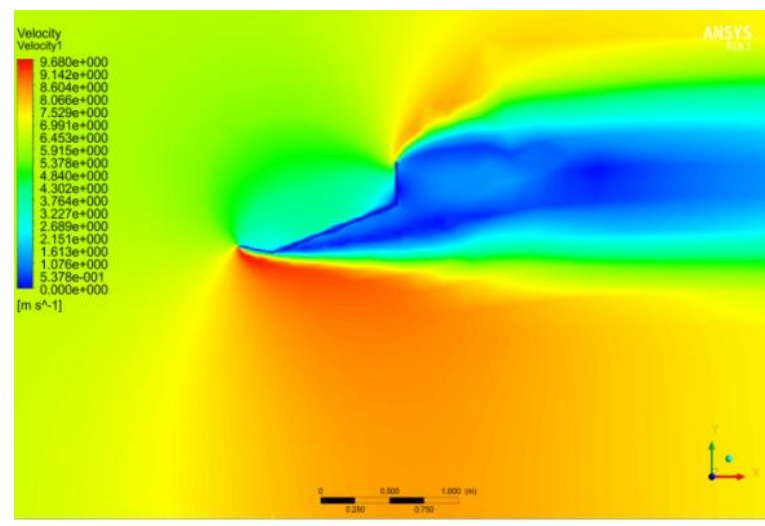

f. Velocity Counters for Diff 3.6

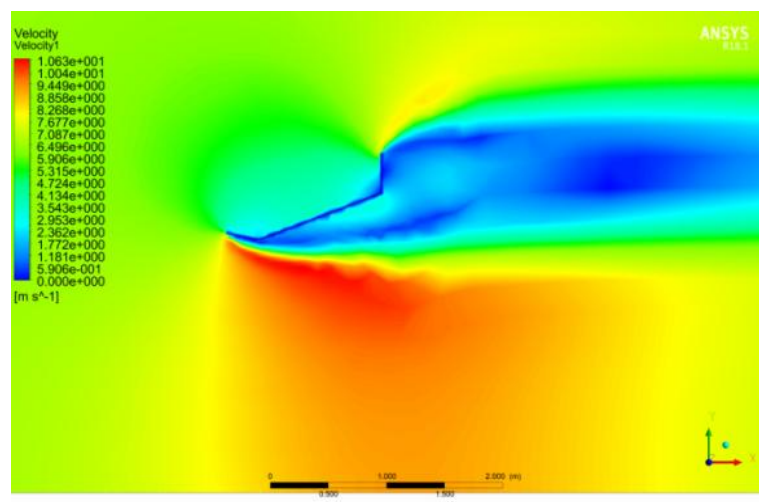

g. Velocity Counters for Diff 4.2

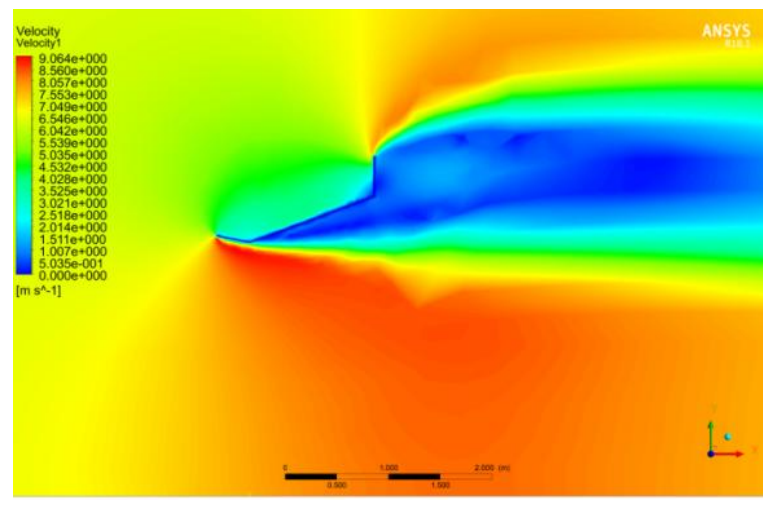

h. Velocity Counters for Diff 4.8

\section{Published By:}

Blue Eyes Intelligence Engineering

\& Sciences Publication 


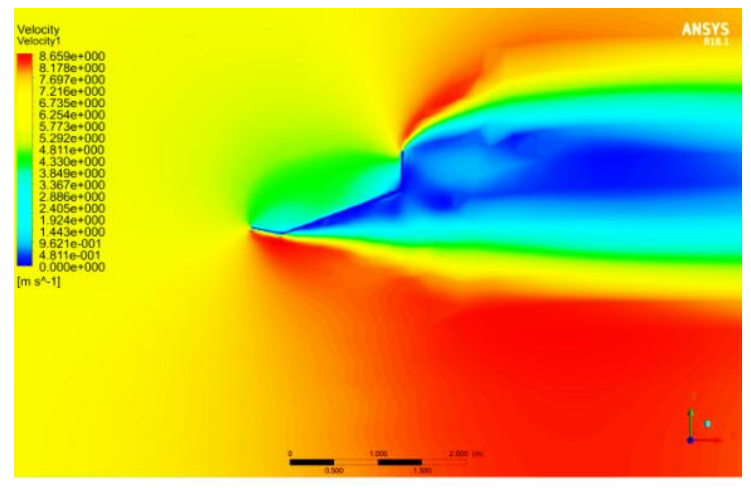

i. Velocity Counters for Diff ${ }_{5.4}$

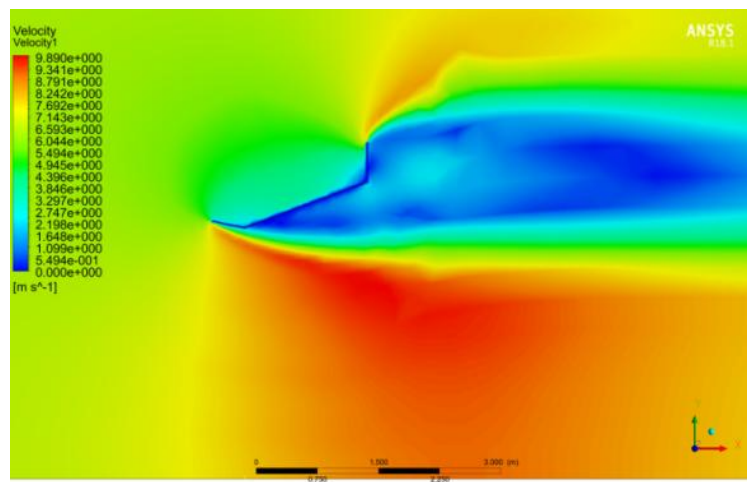

j. Velocity Counters for Diff 6.0

Fig. 1. Velocity Counters for all diffusers

\section{RESULTS AND DISCUSSION}

Fig. 2 is plotted based on the velocity distribution occurred on the diffuser plane up to $0.4 \mathrm{D}$ for all diffusers for the inlet velocity $6.5 \mathrm{~m} / \mathrm{s}$. From the plot it is clearly observed that the values of velocity are reduced with increased in the diffuser diameter. For smallest considered diameter $\left(\operatorname{Diff}_{0.6}\right)$ the wind velocity is $8.32 \mathrm{~m} / \mathrm{s}$ at the central axis of the diffuser. It increases up to $9.32 \mathrm{~m} / \mathrm{s}$ measured at distance $0.4 \mathrm{~m}$ from the central axis. For biggest considered diameter $\left(\right.$ Diff $\left._{6.0}\right)$ the wind velocity is $7.33 \mathrm{~m} / \mathrm{s}$ at the central axis of the diffuser. It increases up to $7.86 \mathrm{~m} / \mathrm{s}$ measured at distance $0.4 \mathrm{~m}$ from the central axis. The difference in inlet velocity and increase velocity is found at 2.18 for $\operatorname{Diff}_{0.6}$ and 1.16 for $\operatorname{Diff}_{6.0}$

Fig. 3 presents the theoretical power output for the bare wind turbine and DAWT at wind velocity $6.5 \mathrm{~m} / \mathrm{s}$ for all diffusers. Since all DAWT power values are on the higher side compared to bare wind turbine power output. With the increase in diffuser diameters the velocity values are reduced for the same input values. In spite of this, it is observed that with increase in diffuser diameter, for the considered range it produces significant ore power than the bare wind turbine.

Fig. 4 is the plot of multipliers increase in velocity, power and $C_{p}$ for DAWT at wind velocity $6.5 \mathrm{~m} / \mathrm{s}$ with respect to bare wind turbine for all diffusers. With an increase in rotor diameter, multipliers of velocity, power output and coefficient of performance are decreasing. The multiple increase in velocity is found as 1.34 for Diff $_{0.6}$ and 1.18 for Diff $_{6.0}$. The multiple increase in power output is found as 2.38 for Diff $_{0.6}$ and 1.64 for Diff ${ }_{6.0}$. The multiple increase in coefficient of performance $\left(\mathrm{C}_{\mathrm{p}}\right)$ is found as 1.62 for Diff $_{0.6}$ and
1.11 for $\operatorname{Diff}_{6.0}$.

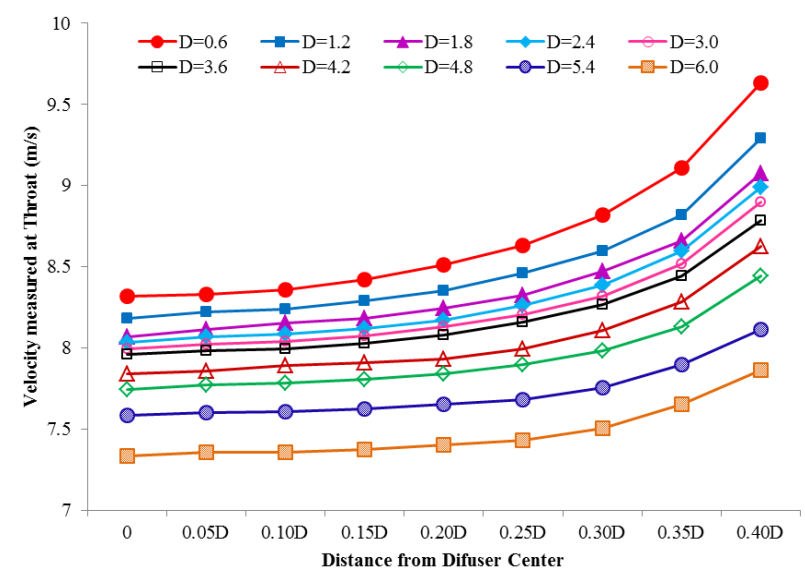

Fig. 2. Velocity distribution at throat for all diffusers

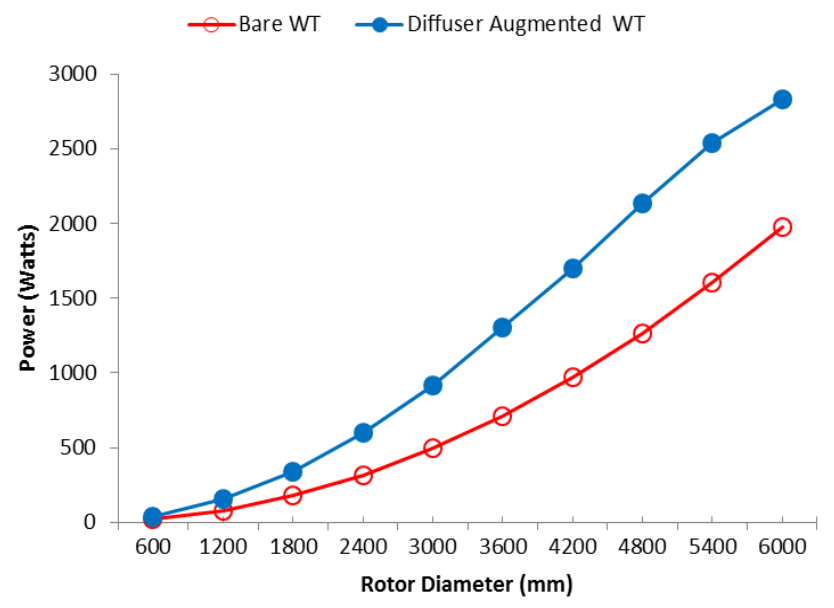

Fig. 3. Theoretical power output for bare wind turbine and DAWT at wind velocity $6.5 \mathrm{~m} / \mathrm{s}$ for all diffusers

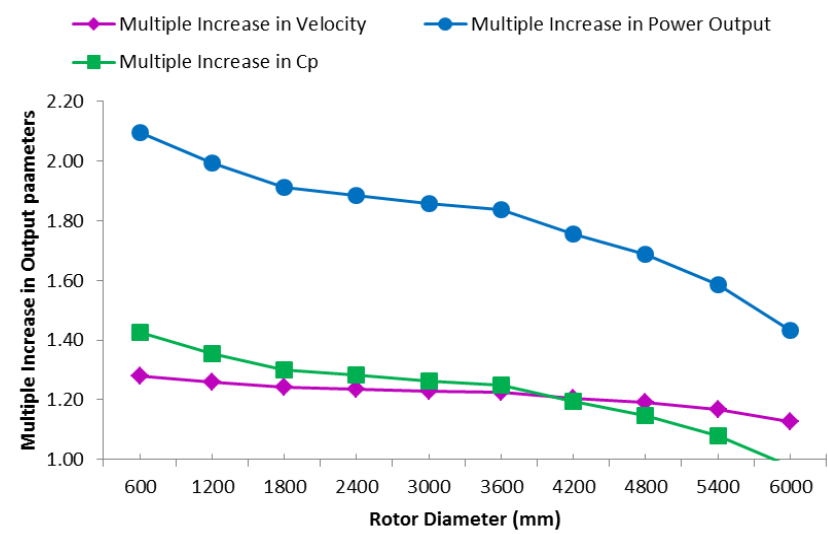

Fig. 4. Multipliers increase in velocity, power and $C_{p}$ for DAWT at wind velocity $6.5 \mathrm{~m} / \mathrm{s}$ with respect to bare wind turbine for all diffusers

Though, it is observed that the values of multipliers re decreasing, it cannot be declared that the diffusers are efficient for smaller diameter range. The evaluation presented in this research paper is a basic evaluation, but important for further research. This evaluation is based only on increasing the

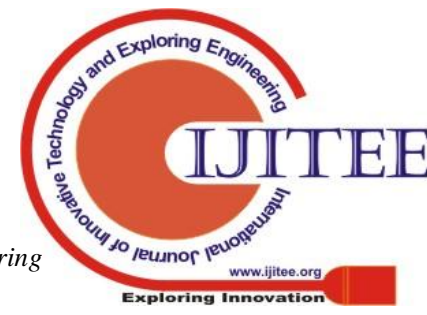


diffuser diameters.

Still, there are many factors which can be jointly considered for comprehensive evaluation for wind turbines of various rotor diameters.

\section{CONCLUSION}

From the computational analysis carried for diffusers of similar geometry with different diameters following conclusions are listed,

- With an increase in diffuser diameter the values of velocity obtained are reduced.

- The multiple increase in velocity is found as 1.34 for Diff $_{0.6}$ and 1.18 for $\operatorname{Diff}_{6.0}$.

- The multiple increase in power output is found as 2.38 for $\operatorname{Diff}_{0.6}$ and 1.64 for $\operatorname{Diff}_{6.0}$.

- The multiple increase in coefficient of performance $\left(\mathrm{C}_{\mathrm{p}}\right)$ is found as 1.62 for $\operatorname{Diff}_{0.6}$ and 1.11 for Diff 6.0 .

\section{REFERENCES}

1. Mahasidha Birajdar, S. A. Kale, S.N. Sapali, "Effects of Design Parameters on Aerodynamic Performance of New Profile Small Wind Turbine Blades", ASME 2015 International Mechanical Engineering Congress and Exposition, Houston, Texas, USA, November 13-19, 2015, ISBN: 978-0-7918-5747-2, pp. V07BT09A049; 8 pages

2. Nemat Keramat Siavash, Gholamhasan Najafi, Teymur Tavakoli, Barat Ghobadian, Esmail Mahmoodi, "An Innovative Variable Shroud for Micro Wind Turbines, Renewable Energy" (2019), doi: 10.1016/j.renene.2019.06.098

3. Jerson R.P. Vaz, David H. Wood, "Aerodynamic optimization of the blades of diffuser-augmented wind turbines", Energy Conversion and Management 123 (2016) 35-45

4. Vaz J R P, Wood D H, "Effect of the diffuser efficiency on wind turbine performance", Renewable Energy (2018), doi: 10.1016/j.renene.2018.04.013

5. Swanand Kulkarni, S. A. Kale, Prakash Dabeer, Suresh M Sawant, "Comprehensive Evaluation of Some Innovative Wind Turbines", ASME 2015 International Mechanical Engineering Congress and Exposition, Houston, Texas, USA, November 13-19, 2015, ISBN: 978-0-7918-5757-1, pp. V014T06A006; 11 pages

6. S. A. Kale, S.N. Sapali, "Development and Field Testing of an Inclined Flanged Compact Diffuser for a Micro Wind Turbine", ASME 2014 International Mechanical Engineering Congress and Exposition, Montreal, Canada, November 14-20, 2014, ISBN: 978-0-7918-4952-1, pp. V06BT07A070; 6 pages

7. Kale S. A., Yogesh Gunjal, Sachin Jadhav, Ajinkya Tanksale, "CFD Analysis for Optimization of Diffuser for a Micro Wind Turbine", IEEE Xplore Digital Library, ISBN: 978-1-4673-6149-1, DOI 10.1109/ICEETS.2013.6533392, pp. 257-260, 2013

8. Maskepatil L.P Gandigude, A. U, Kale S. A, "Selection of Material for Wind Turbine Blade by Analytic Hierarchy Process (AHP) Method", Applied Mechanics and Materials, Volume 612, Pages 145-150, DOI: 10.4028/www.scientific.net/amm.612.145

9. Haribhau G. Phakatkar, Rushikesh V. Godse, Sandip A. Kale, Mahasidha R. Birajdar, "Computational Flow Analysis of Straight Converging-Diverging, Vertical Flanged Diffusers for a Small Wind Turbine", International Journal of Recent Technology and Engineering, Volume-8, Issue-1S4, June 2019, pp. 1035-1042

10. Khamlaj TA, Rumpfkeil MP, "Analysis and optimization of ducted wind turbines", Energy (2018), doi: 10.1016/j.energy.2018.08.106. 